\title{
Correlation of Career Stress, Department Satisfaction, and SCL-90-R of Students Specialized in Dental Hygiene
}

\author{
Jong Hwa Yum, Hyo-jin Ko and Hye Jin Kim ${ }^{\dagger}$ \\ Department of Biomedical Health Science, Dong-Eui University, Busan, Korea \\ khj1126@deu.ac.kr
}

\begin{abstract}
This study was investigated to evaluate that influence career stress, department satisfaction, and psychological state among dental hygiene students. This cross-sectional questionnaire research was conducted with 365 dental hygiene students in Busan and Ulsan from March and May 2013. Data analysis was performed with frequent analysis, t-test, ANOVA, correlation analysis using the SPSS ver. 21. According to the result, mothly income and the career aptitude and career related characteristics associated with career stress, department satisfaction, and psychological effects on the state insane. There is a positive correlation between career stress and $S C L-90-R(p<.01)$, and a negative correlation between department satisfaction and SCL-90-R ( $p<.05, p<.001)$. Thus, psychological and social support will need for students belonging to families in need. It is also necessary to activate various counseling programs with experts in seeking career guidance and counseling.
\end{abstract}

Keywords: Career stress, Department satisfaction, Symptom check list-90-revision

\section{Introduction}

Mental health can be defined as the ability to develop and maintain satisfying relationships by adequately dealing with daily stress and needs[1]. According to the yearly suicide ideation in university students in Korea reported by the Ministry of Education in 2011, the number has increased from 191 in 2006 to 332 in 2008 (an average of 230 suicide student increase) [2]. This report shows that the stress of university students is seriously at risk. Many university students are pleading for help because of problems with romance, school, career and employment, relationships, finance, and view of value [3]. Among them, career and employment problem is the biggest and considered a significant problem that can even bring a change in the university students' school life [4]. Although contemplating about employment and career plan is common, except for certain cases, the students in the school of dental hygiene have a positive outlook about their future when they are first admitted. Nonetheless, they are stressed after studying specialized subjects in their curriculum or for license exam and a fluctuation in health personnel employment. Thus, students majoring in dental hygiene are not exempt from stress as they experience serious agony related to career due to the heightened employment competitiveness. According to the result of a study, career stress is increased the lower department satisfaction is also reported [5]. The career or jobs that an individual has selected define one's department, and this is clearly reflected in major satisfaction. Major satisfaction can have a positive effect on career development after graduation, and the subjective experience about a major is caused by the interplay of environmental and psychological factors of the department [6]. University students' positive outlook related to their department satisfaction can be seen in their pride for the school; in contrast, a negative outlook can lead to leave of absence, dropping out, and transferring. The 
importance of department satisfaction is extremely high. Career stress that can influence their study motive, university life adjustment, quality of life, career decision; barriers to the career should be relieved, and department satisfaction related to curriculum, study environment, and relationships should be improved. Such factors should be well balanced, and methods to help the students adjust to their university life with a stable mental state should be investigated. Symptom Check List-90-Revision(SCL-90-R) [7] and Minnesota Multiphasic Personal Inventory (MMPI) [8] are often used in Korea for studies on university students' overall psychological state. Although there are studies on career stress [5,9] career awareness of dental hygiene students [10] the influence of subject satisfaction and career efficacy on career exploration behaviors [11] department satisfaction [5,12] and relationship between emotional awareness and career satisfaction [13], there are scarce studies on the overall psychological state related to career stress and department satisfaction. Therefore, the study recognizes the career stress, subject satisfaction, and mental health status of dental hygiene students and defines their relation and negative factors to examine the methods that help students live a more satisfying university life by having more stable psychological state and adequate life value.

\section{Subjects and Method}

\subsection{Subjects}

The study was conducted with randomly selected students from the School of Dental Hygiene of four different universities in Busan and Ulsan area between March and May 2013. A total of 468 data were collected but only 365 of them were used after discarding 103 results that were inappropriate for data processing.

\subsection{Methods}

The survey is composed of 4 general characteristics, 5 career-related characteristics, 12 career stress questions, 22 department-satisfaction questions, and 90 SCL-90-R questions. General characteristics were related to school year, monthly income, method of tuition payment, and residence. Career-related characteristics are institution of your desire, location of your employment, desired work period, job selection criteria, and career aptitude. For career stress, a measuring tool used in Yoo-jin Seo [12]'s study was used. There are a total of 12 questions where the higher the Likert 5-point scale score, the higher the career stress level (Cronbach's' $\alpha=.889$ ). For department satisfaction, a tool used in Hye-sook Ha [13]'s study was modified and used. There are a total of 22 questions where the higher the Likert 5-point scale score, the higher the major satisfaction (Cronbach's' $\alpha=.921$ ). For mental health, the revised Symptom Check List-90-Revision(SCL-90-R) based on Symptom Check List (SCL90) developed from Hopkins Symptom Check List(HSCL) was used[14]. It is composed of nine different categories: somatization, obsessive-compulsive, interpersonal sensitivity, depression, anxiety, hostility, phobic anxiety, paranoid ideation, and psychoticism. The scores from each category were converted into an average T-score where the lower the score, the healthier the mental state (Cronbach's' $\alpha=.979)$.

\subsection{Statistical Analysis}

Collected data were analyzed with the SPSS ver. 21, and frequent analysis was conducted for the general characteristics and career-specialized characteristics. The t-test and ANOVA were conducted for career stress, department satisfaction, and SCL-90-R according to the general and career-specialized characteristics; Duncan test was conducted thereafter. An 
analysis of correlation was conducted to examine the relevance between career stress, department satisfaction, and SCL-90-R.

\section{Results}

\subsection{General and Career-Related Characteristics}

There were 365 subjects; most of them were second year students (166 students, 45.5\%). As for the monthly income, most of them had lower than 3000 dollars (148 students, $40.5 \%$ ), and 284 students' tuition was paid by their parents (77.8\%). As for residency, home had the highest answer with 216 people (59.2\%). Most students (139 students) answered dentist for their desired job (38.1\%); 199 answered near home as workplace (54.53\%); 258 answered life-long work period $(70.7 \%)$. The students considered "organization atmosphere" (182 answers, $49.9 \%$ ) the most when finding a job. "Average" was the most common answer for aptitude question (195 answers, 53.4\%)

\subsection{Average of Measuring Tools}

The career stress of the subjects was $2.95 \pm 0.68$. Curriculum satisfaction among department satisfaction criteria was $3.45 \pm 0.52$, relation satisfaction was $3.31 \pm 0.58$, general satisfaction was $3.46 \pm 0.54$, and social satisfaction was $3.82 \pm 0.61$. For the SCL-90-R, somatization had the highest score $55.70 \pm 13.06$, followed by obsessive-compulsive $55.16 \pm 10.46$, interpersonal sensitivity $54.77 \pm 12.27$, paranoid ideation $54.02 \pm 17.76$, hostility $53.47 \pm 16.18$, depression $52.22 \pm 11.23$, anxiety $50.62 \pm 12.98$, psychoticism $48.91 \pm 17.81$, phobic anxiety $48.38 \pm 24.23$.

\subsection{Career Stress and Department Satisfaction by Characteristics}

Career stress according to the general characteristics was higher when the monthly income was lower than 3000 dollars (3.07 \pm 0.65$)$ than when the monthly income was between 3000 and 4000 dollars $(2.84 \pm 0.63)$ and higher than 4000 dollars $(2.91 \pm 0.75)(\mathrm{p}<.05)$. Department satisfaction according to the general characteristics was higher when the monthly income was between 3000-4000; curriculum satisfaction was 3.55 \pm 0.50 , which was also higher for those with monthly income lower than $3000(3.42 \pm 0.50)$ and those with monthly income higher than $4000(3.36 \pm 0.54)(p<.05)$. For general satisfaction, those with monthly income between 3000 and 4000 dollars had the highest score $(3.55 \pm 0.52)$, followed by those with monthly income lower than $3000(3.46 \pm 0.53)$ and higher than $4000(3.35 \pm 0.58)(\mathrm{p}<.05)$.

With regard to stress related to career, most dental hygiene students answered "unfitting" for aptitude (3.24 \pm 0.71$)$, followed by "average" (3.01 \pm 0.56$)$ and "very fitting" $(2.61 \pm 0.73)$. This indicates that the more fitting the study, the lower the career stress level $(\mathrm{p}<.001)$. For department satisfaction related to career, relation satisfaction was 3.36 \pm 0.58 , and general satisfaction was $3.51 \pm 0.52$ for those who answered "life-long" as their desired work-period; this score was higher than that of those who answered "before marriage" or "after marriage"; thus, the longer the expected work-period, the higher the satisfaction. In the case of those who answered "organization atmosphere" as their criteria of choosing a job, curriclum satisfaction was $3.52 \pm 0.52$ and social satisfaction was $3.92 \pm 0.54$; this was higher than that of those who answered "compensation," "working environment." or "social status" $(\mathrm{p}<.05)$. Their aptitude for dental hygiene had the highest score those who answered "very fitting" had $3.62 \pm 0.49$ for curriculum satisfaction, $3.49 \pm 0.53$ for relation satisfaction, $3.89 \pm 0.47$ for general satisfaction, and $4.09 \pm 0.57$ for social satisfaction, which were all higher than the scores of those who answered "unfitting" or "average"; therefore, the more fitting you feel for your major, the higher the department satisfaction $(\mathrm{p}<.001)$. 


\section{Table 1. Correlation Coefficients between Career Stress, Department Satisfaction and SCL-90-R}

\begin{tabular}{lccccc}
\hline \multicolumn{1}{c}{ Variables } & Career Stress & $\begin{array}{c}\text { Curriculum } \\
\text { Satisfaction }\end{array}$ & $\begin{array}{c}\text { Relation } \\
\text { Satisfaction }\end{array}$ & $\begin{array}{c}\text { General } \\
\text { Satisfaction }\end{array}$ & $\begin{array}{c}\text { Social } \\
\text { Perception }\end{array}$ \\
\hline SOM & $.175^{* *}$ & $-.198^{* *}$ & $-.157^{* *}$ & $-.147^{* *}$ & $-.209^{* *}$ \\
O-C & $.422^{* *}$ & $-.119^{*}$ & $-.116^{*}$ & $-.141^{* *}$ & -.080 \\
I-S & $.354^{* *}$ & -.093 & $-.134^{*}$ & $-.126^{*}$ & -.097 \\
DEP & $.390^{* *}$ & $-.159^{* *}$ & $-.130^{*}$ & $-.215^{* *}$ & -.100 \\
ANX & $.279^{* *}$ & $-.220^{* *}$ & $-.168^{* *}$ & $-.220^{* *}$ & $-.234^{* *}$ \\
HOS & $.252^{* *}$ & $-.198^{* *}$ & $-.193^{* *}$ & $-.227^{* *}$ & $-.199^{* *}$ \\
PHOB & $.178^{* *}$ & $-.216^{* *}$ & $-.182^{* *}$ & $-.199^{* *}$ & $-.272^{* *}$ \\
PAR & $.334^{* *}$ & $-.140^{* *}$ & $-.121^{*}$ & $-.172^{* *}$ & $-.166^{* *}$ \\
PSY & $.329^{* *}$ & $-.170^{* *}$ & $-.126^{*}$ & $-.194^{* *}$ & $-.197^{* *}$ \\
\hline p<.05, p $p<.01$ & & & & &
\end{tabular}

\subsection{SCL-90-R by Characteristics}

In the SCL-90-R according to general characteristics, the T-score of depression was $54.08 \pm 10.28$ for those with monthly income lower than 3000 ; this score was higher than the $\mathrm{T}$-scores of those with monthly income between 3000 and $4000(50.49 \pm 10.40)$ and higher than 4000 (51.48 \pm 13.08$)$. Interpersonal sensitivity had the highest $T$-score $(55.53 \pm 9.09)$ when the tuition was paid with student loans $(\mathrm{p}<.05)$.

In the SCL-90-R according to career-related characteristics, the T-score of anxiety in those who answered general hospital as their desired institution was 53.12 \pm 17.18 , which was higher than those who answered public organizations, large dental clinic, or dental office. The Tscore of paranoia in those who answered public organizations was $57.29 \pm 16.22$ and general hospital was 56.64 \pm 15.81 ; these scores were higher than the scores of those who answered large dental clinic and dental office $(\mathrm{p}<.05)$. The $\mathrm{T}$-score of anxiety for those who answered "compensation" as the reason for choosing a job was $53.03 \pm 13.02$, and this score was higher

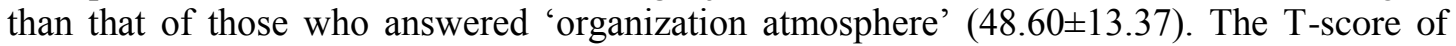
hostility for those who answered 'work environment' as the reason for choosing a job was $56.85 \pm 11.46$, which was higher than that for those who answered 'organization atmosphere' $(50.91 \pm 16.57)(\mathrm{p}<.05)$. Those who answered that dental hygiene was "unfitting" for their aptitude had a score of $56.62 \pm 10.62(\mathrm{p}<.001)$ for depression, $57.50 \pm 10.69$ for obsessive compulsive, $58.64 \pm 13.06$ for interpersonal sensitivity, $57.70 \pm 15.44$ for hostility $(\mathrm{p}<.01)$, $53.77 \pm 13.62$ for anxiety, and $53.47 \pm 23.77$ for phobic anxiety $(\mathrm{p}<.05)$; this indicates that the more fitting the major, the lower the T-score

\subsection{Correlation between Career Stress, Department Satisfaction, and SCL-90-R}

This study showed a significant positive correlation between SCL-90-R and career stress $(\mathrm{p}<.01)$, and a negative correlation between department satisfaction and SCL-90-R ( $<<.05$, $\mathrm{p}<.001)<$ Table 1>; thus, the higher the career stress, the higher the T-score for the SCL-90$\mathrm{R}$, and the higher department satisfaction, the lower the T-score for the SCL-90-R<Table 1>. 


\section{Discussion}

The study was conducted to provide basic information that can be utilized for career counseling, career planning, and student counseling by understanding the general mental stage of dental hygiene students with career stress, department satisfaction, and SCL-90-R.

The study results showed that the career stress of dental hygiene students was average, and although there was a slight difference, these results were similar to Sun-Hyang Shin[15]'s study conducted on health science college students composed mostly of females and Yoo-Jin Seo[12]'s study conducted on university students. Department satisfaction's sub-scores were all similar to Jin-Hee Lee[16]'s results except the social percoption, which had a slightly higher score. It is considered that such result is reflecting the increased social awareness ability due to positive evaluation of employment security and various related situations that had been derived from students deciding their majors, focusing mainly on employment due to economic downturn and recession causing youth unemployment.

SCL-90-R of dental hygiene students was evaluated as follows: somatization (55.70), obsessive compulsive (55.16), interpersonal sensitivity (54.77), paranoid ideation (54.02), hostility (53.47), depression (52.22), anxiety (50.62), and psychoticism (48.91); the overall scores are relatively higher than but similar to the results of Sun-Min Park's study conducted on health science university students [obsessive compulsive (51.96), interpersonal sensitivity (49.44), depression (48.73), paranoid ideation (48.09), anxiety (47.70), psychoticism (47.44).

The results of department-specific career stress and subject satisfaction, as well as SCL-90$\mathrm{R}$ claim that the dental hygiene students who answered "fitting" for aptitude for their major had low career stress $(\mathrm{p}<.001)$, high department satisfaction $(\mathrm{p}<.001)$, and low T-scores for each category of SCL-90-R, indicating that their general psychological state is stable. YoungSoon Young and Mee-Hee Jeong[10]'s study examining dental hygiene student's subject satisfaction showed similar result; those who have an aptitude for their major have a high department satisfaction. Accordingly, the student's general university life adaptation and satisfaction levels will be high and the student will be able to finish the course of study with more stable mental state, when aptitude is considered the most important factor for choosing a major. Those who consider "dental hygienists" their life-long career and organization atmosphere the most important factor show high curriculum and social perception. This shows that a proactive attitude of a professor is needed to help students realize an appropriate occupational value and pride so that a more effective education can be made.

An analysis of correlation between career stress, department satisfaction, and amination showed that the higher career stress, the more unstable the mental state, and the higher the department satisfaction, the more stable the mental state. This was similar to Sun-Min Park[6]'s study claiming the higher T-score for all categories except hostility, and the higher career stress was for female students majoring in the health science field. Accordingly, efforts are needed to lower career stress and improve department satisfaction for a more stable mental state of dental hygiene students.

Since the study was only conducted on dental hygiene students from certain areas, it is therefore difficult to generalize the results. Additionally, the study is limited because of the lack of various variables that can affect physical health, occupational value, career stress, department satisfaction, and mental health. Therefore, future studies need to consider more variables and need not only be conducted on health science students but also to be compared with other general university students as well.

In conclusion, choosing a major that is fitting for an individual significantly influences career stress, subject satisfaction, and mental state. Thus, it is crucial to emphasize the importance of choosing a major based on one's aptitude to effectively cultivate professionals. 
Additionally, students' career stress needs to be minimized, and department satisfaction needs to be maximized for students to complete dental hygiene curriculum with a more stable mental state. Furthermore, continuous attention and support, such as placement of professionals, management of group counseling program, and other active involvement is needed.

\section{Conclusion}

In the survey on students studying at the department of dental hygiene in Busan and Ulsan area from March to May 2013 to examine variables that influence career stress, department satisfaction, and general mental state, the following results were obtained:

1. Career stress was significantly high for those with monthly income lower than 3000 dollars $(\mathrm{p}<.05)$ and for those who thought dental hygiene was unfitting for them $(\mathrm{p}<.001)$. Subject satisfaction was high, if the monthly income was between 3000 and $4000(\mathrm{p}<.05)$, the student thought of work period as life-long $(\mathrm{p}<.05)$, the reason for choosing a job was "organization atmosphere" ( $\mathrm{p}<.05)$, and if the student thought that dental hygiene is fitting for their aptitude $(\mathrm{p}<.001)$.

2. As for the SCL-90-R, when the monthly income was lower than 3000, depression was high $(\mathrm{p}<.05)$; when tuition was paid with student loan, interpersonal sensitivity was high $(\mathrm{p}<.05)$; if the desired workplace was either general hospital or public institution, anxiety and paranoid ideation were high $(\mathrm{p}<.05)$; if the reason for choosing a job was working environment, hostility was high $(\mathrm{p}<.05)$; and the level of aptitude that the dental hygiene students have about their major, influenced depression $(\mathrm{p}<.001)$, obsessive compulsive, interpersonal sensitivity, and hostility $(\mathrm{p}<.01)$, as well as anxiety and phobic anxiety $(\mathrm{p}<.05)$.

3. The correlation between career stress, dpartment satisfaction, and SCL-90-R was analyzed to determine their relationship. According to the result, there is a positive correlation between career stress and SCL-90-R ( $\mathrm{p}<.01)$, and a negative correlation between department satisfaction and SCL-90-R ( $\mathrm{p}<.05, \mathrm{p}<.001)$.

Ultimately, an aptitude should be the first considered in order to reduce career stress, improve department satisfaction, and complete the curriculum with more stable mental state. Moreover, psychological and social support is needed for students belonging to families in need. It is also necessary to activate various counseling programs with experts in seeking career guidance and counseling.

\section{References}

[1] M. Kong and Y.J. Kang, J. Rehabilitation Psychology, vol. 19, (2012), p. 1

[2] Survey on Ministry of Basic Education http://std.kedi.re.kr (2011)

[3] J. H. Lee, K. Y. Jeoung and H. J. Yu, J. Korea Youth Research Association, vol.14, (2007), p. 407

[4] J. Sookmyung Women's University of Student life counseling center. (2008)

[5] J. H. Yum, H. J. Ko and H. J. Kim, J. Advanced Science and Technology Letters, vol. 33, (2013), p. 37

[6] S. M. Park, Graduate School, Kyungpook National University, Daegu (2009)

[7] G. I. Kim, J. H. Kim and J. H. Nam. et al, Mental Health Research $7^{\text {th }}$, (1988), pp. 86-102

[8] J. H. Lee, B. T. Park, J. B. Lee and S. D. Jung, J. Yeungnam University, vol.5, (1988), p. 141

[9] E. Y. Yu, J. Korea Contents Association, vol. 9, (2009), p. 718

[10] Y. S. Won and M. H. Jung, J. Dental Hygiene Science, vol. 4, (2004), p. 85

[11] J. S. Yu and S. Y. Choi, J. Dental Hygiene Science, vol. 10, (2010), p. 307

[12] E. G. Seo, Graduate school, Catholic University, Seoul, (2006).

[13] H. S. Ha, Graduate school, Seoul National University, Seoul (2000).

[14] G. I. Kim, J. H. Kim and H. T. won, Guidelines for SCL-90-R, First edition, Seoul (1984).

[15] S. H. Shin, J. Dental Hygiene Science, vol. 12, (2012), p. 217.

[16] J. H. Lee, Graduate School, Kangwon National University, Chuncheon (2008). 


\section{Authors}

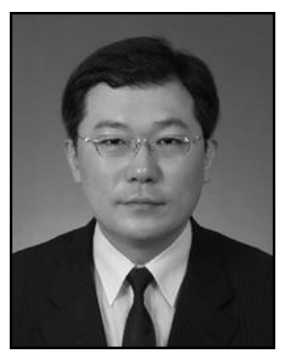

\section{Jong Hwa Yum}

1 Feb. 1990 - 6 Aug. 1994: Department of Bacteriology at National Institute of Health (NIH) in Korea.

19 Feb. 1998: Ph.D. degree at Dankuk University in Korea.

1 Mar. 2008 - recent: assistant professor Dong-eui University in Korea.

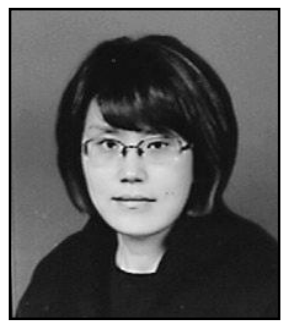

\section{Hye Jin Kim}

19 Feb. 2004: Ph.D. degree at Keimyung University in Korea.

3 Mar. 2010 - 2 Feb. 2012: assistant professor Baekseok University in Korea

1 Mar. 2012 - recent: assistant professor Dong-eui University in Korea.

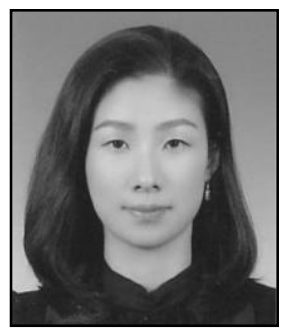

\section{Hyo Jin Ko}

8 Aug. 2008 - 8 Aug. 2010 : Master degree at Kosin University in Korea.

3 Mar. 2013 - recent: Ph.D. at Department of Biomedical Health Science, Dong-eui University in Korea. 
International Journal of Bio-Science and Bio-Technology Vol.6, No.3 (2014) 